\title{
Repertório comum colaborativo de práticas de aprender-fazendo: cartografando parentescos
}

\author{
Common collaborative repertoire of learning-by-doing practices: mapping kinships
}

Bianca Martins

design, educação, design participativo, aprender-fazendo, cartografia

Quais estratégias de produção coletiva, em contexto de isolamento social, podem ser úteis a um jovem grupo de pesquisadores, na intenção de formular uma rede de conhecimentos e dispositivos para ação no cenário do design envolvido com questões educativas? Como elaborar de forma colaborativa um repertório de conceitos comuns e que proporcionem sinergia às suas pesquisas situadas em diferentes regiões do Brasil? Estas foram as questões disparadoras deste artigo que apresenta o processo de elaboração e síntese gráfica coletiva de uma teia de conceitos que sustentam e oportunizam as ações do Grupo de Pesquisa Design \& Escola ESDI/UERJ composto por pesquisadores do Rio de Janeiro, Paraná e Minas Gerais. A atividade, desenvolvida durante o contexto de isolamento social devido à pandemia de COVID-19, teve como base os pressupostos do método da cartografia e lançou mão de estratégias de trabalho colaborativo remoto. Descrevemos a constituição e os propósitos do grupo, os enfoques metodológicos, os recursos técnicos que sustentaram as ações e pesquisas e como esses valores foram traduzidos nas interações e sínteses gráficas cartografadas colaborativamente pelos integrantes do grupo.

design, education, participatory design, learning by doing, cartography method

Which collective production strategies, in the context of social isolation, can be useful to a young group of researchers, with the intention of formulating a network of knowledge and devices for action in the design scenario involved with educational issues? How to cocreate a repertoire of common concepts that provide synergy to researchers located in different regions of Brazil? These were the triggering questions of this article that presents the collaboratively elaboration process and graphic synthesis of a web of concepts that support and provide opportunities for actions by Design Research Group at the ESDI / UERJ School, composed by researchers from Rio de Janeiro, Paraná and Minas Gerais. The activity, developed during contingencies of social isolation due to the COVID-19 pandemic, was based on the assumptions of the cartography method and used remote collaborative work strategies. We describe the constitution and purposes of the group, the methodological approaches, the technical resources that supported the actions and research and how these values were translated into the interactions and graphical syntheses collaboratively mapped by the members of the group.

\section{Introdução}

O desenvolvimento dos artefatos narrados neste artigo tem origem nas atividades atreladas ao projeto de extensão Usos do Design na escola: Articulação entre Universidade e Escola para implementar práticas, recursos e espaços de aprendizagem mais instigantes vinculado ao

Anais do $10^{\circ} \mathrm{CIDI}$ e $10^{\circ} \mathrm{CONGIC}$

Kelli C.A.S. Smythe, Rafael de Castro Andrade (orgs.)

Sociedade Brasileira de Design da Informação - SBDI

Curitiba | Brasil | 2021
Proceedings of the $10^{\text {th }} \mathrm{CIDI}$ and $10^{\text {th }}$ CONGIC

Kelli C.A.S. Smythe, Rafael de Castro Andrade (orgs.)

Sociedade Brasileira de Design da Informação - SBDI Curitiba | Brazil | 2021 
DesEduca lab - Laboratório Design e Educação da ESDI/UERJ. Tendo iniciado em outubro de 2019 , o projeto foi totalmente adaptado às contingências de isolamento social por conta da pandemia, a partir de março de 2020. Se antes o contexto de pesquisa envolvia atividades integrando pesquisadores e alunos da ESDI junto às comunidades das escolas públicas do Rio de Janeiro, com a suspensão das atividades presenciais a proposta de articulação e fertilização mútua de práticas educativas, objetos e estratégias de ensino-aprendizagem precisou adaptarse ao contexto de ação remota. A primeira medida foi estabelecer, no contexto do Laboratório Design e Educação da ESDI/UERJ, um Grupo de Estudos com o objetivo de investigar e elencar conceitos e práticas convergentes, do campo da Educação e do Design, que oportunizassem o uso do pensamento projetual/design em aprendizagens inventivas.

Este artigo narra os procedimentos metodológicos adotados para a construção colaborativa e remota de um repertório comum de conceitos e práticas de aprender-fazendo, ou seja, o uso de estratégias de aprendizagem onde haja a exploração do pensamento projetual no sentido de instigar habilidades de prototipação de ideias para a resolução de problemas complexos e/ou no estímulo a abordagem de situações de produção de sentido. Em qualquer das possibilidades valoriza-se a colaboração entre designers e educadores na proposição de práticas instigantes de ensino-aprendizagem.

\section{Enfoques metodológicos}

O repertório de experiências e vocação do grupo é notoriamente influenciado pelos valores da práxis transformadora, onde ação e reflexão acontecem em uma unidade dialética (FREIRE, 1960), e pelo design participativo centrado na comunidade que incorpora a prática de imersão em campo usando conhecimentos de design para projetar com a comunidade, cocriando possibilidades de solução coerentes com o contexto (Cantù et al., 2012).

Esse perfil de atuação manifesta a inseparabilidade entre conhecer-fazer; pesquisarintervir. Nessa postura de investigação toda pesquisa é considerada uma intervenção na situação abordada. Conforme Kastrup \& Passos (2014), no desenrolar de uma pesquisaintervenção acontece também o agenciamento entre sujeito, objeto, teoria e prática, ou seja: o pesquisador está sempre implicado no campo de investigação e a intervenção modifica o objeto e o próprio pesquisador. A pesquisa-intervenção pressupõe, ainda, que no plano da experiência, onde conhecer e fazer são inseparáveis, não há espaço para a neutralidade ou a concepção de sujeitos ou objetos prévios à relação que os liga.

Partindo desses pressupostos, e levando em consideração a diversidade dos integrantes do grupo - a saber 19 pessoas provenientes dos campos do Design e da Educação, sendo 5 deles/as professoras da Rede Pública de Educação Básica, habitantes das cidades do Rio de Janeiro/RJ, Curitiba/PR e Santos Dumont/MG - a equipe tinha noção de que precisaria construir colaborativamente um repertório comum que orientasse o trabalho com práticas de aprender-fazendo. Contudo, estava claro que tal repertório não seria, de forma alguma, um conjunto de estratégias ou ferramentas concebidas de forma prévia para serem prescritas em 
situações diversas, como um tool-kit. Não partimos da suposição de que o mundo está dado e que o conhecimento serve para entender esse mundo do jeito que está. Faz parte do perfil do grupo entender que tal repertório de práticas produz subjetividades e mundos, isto é: estas práticas engendram novas facetas a estes sujeitos como também aos artefatos envolvidos nesta ação favorecendo a criação de formas outras de atuar e habitar o planeta (Kastrup, 2001). Logo, estava claro para os participantes do grupo que a proposta teria implicações ético-estético-políticas uma vez que tais práticas aconteceriam a partir de intervenções em contextos educativos buscando incitar dinâmicas transformadoras mediadas pelos conhecimentos do Design.

A cartografia, que a priori compreende a dinâmica de registrar graficamente mapeamentos de territórios, foi apropriada pelo grupo para além desta concepção preliminar. O grupo, como já mencionado, é praticante da perspectiva do Design Participativo, e somando-se a essa abordagem o método cartográfico foi adotado como o enfoque metodológico que melhor expressa a inseparabilidade entre conhecer-fazer e pesquisar-intervir. Conforme Barros \& Passos (2009) cartografar é, antes de mais nada, acompanhar processos.

Guattari (1981), citado por Kastrup \& Passos (2014) destaca o aspecto de transversalidade do método cartográfico como o trabalho de descrever, intervir e criar efeitos-subjetividade, ou seja, a produção de sujeitos que comportam novas concepções da realidade. Nesse sentido, cartografar é acompanhar o traçado do plano/linhas de força de dinâmicas coletivas de comunicação multidimensional. Para o autor, o pensamento não representa e, sim, acompanha o engendramento daquilo que se pensa. A realidade cartografada é constituída por um conjunto de elementos heterogêneos e se apresenta como mapa móvel de linhas que se condensam em extratos em constante rearranjo (Kastrup, 2007). Esse é o aspecto da cartografia que tomamos como referência para o traçado deste repertório comum colaborativo, entre designers e educadores, para pensar-realizar práticas de aprender-fazendo.

Por este motivo, implicados no método da cartografia, buscamos em Kastrup (2007), inspiração para acompanhar o traçado deste repertório comum do grupo no que diz respeito à atenção cartográfica, ou seja, a criação de um território de observações para o desenrolar do trabalho coletivo. Longe de configurar-se como um caminho linear com a intenção de atingir um fim, o percurso de produção de dados no território da pesquisa cartográfica acontece por meio do acompanhamento de pistas no processo em curso. Vale destacar que tal produção de dados, difere da noção de coleta de dados manifestando, novamente, a visão de que conhecer é também agir intencionalmente e esse aspecto põe em evidência a dimensão na qual o conhecimento é produzido pelos sujeitos, ou seja, a dimensão construtivista do conhecimento.

O acompanhamento destas pistas conduz a atenção do cartógrafo que parte de aspectos amplos e difusos em direção a um reconhecimento detalhado da realidade cartografada. Isso também acontece durante uma viagem a um território desconhecido onde partimos de visões abrangentes e superficiais em direção a um conhecimento das singularidades à medida que caminhamos por ruas, frequentamos lugares típicos e conhecemos as peculiaridades de seus habitantes. Nesse sentido, Kastrup (2007) aponta que é possível identificar 4 variedades de 
atenção do cartógrafo percebidas durante um processo cartográfico de pesquisa-intervenção. São eles: o Rastreio: momento de atenção aberta e sem foco; o Toque: onde um processo de seleção é acionado; o Pouso: onde a percepção se fecha em um zoom, um novo território se configura e começam a aparecer os limites e fronteiras; e o Reconhecimento atento: onde ocorre uma reconfiguração do território e passa a ser possível acompanhar um processo especíico com contornos singulares.

Estes 4 funcionamentos da atenção durante o percurso cartográfico descritos acima foram tomados como referência para a produção deste artigo pois, de fato, percebemos o acontecimento desses movimentos no processo de traçado desse repertório comum. Contudo, vale comentar que esse percurso não seguiu rigorosamente uma ordem cronológica, sendo mais valioso considerá-los como performances desempenhadas pelo grupo.

\section{1a performance: Rastreio}

\section{Leituras e sínteses coletivas}

Seguindo as pistas da pesquisa-intervenção iniciamos a produção colaborativa de uma base de conceitos preliminares a partir do debate de literaturas selecionadas pelo grupo. Estas leituras adensaram nosso debate e oportunizaram trocas e ressignificações necessárias à cartografia de um plano comum.

\section{2a performance: Toque}

\section{Representação Gráfica de Síntese}

Após ter debatido essa base preliminar conceitual, seguimos em direção ao entrelaçamento dos conceitos. Para isso lançamos mão de dinâmicas promovidas pelas/os próprias/os integrantes do grupo. Estas dinâmicas de Representação Gráfica de Síntese (RGS) funcionaram como dispositivos metodológicos que favoreceram a catalisação colaborativa de ideias, como será narrado adiante.

\section{3a performance: Pouso}

\section{Mapeamento individual}

Tendo constituído um repertório partilhado no qual cada um se visse representado, se sentindo pertencente e engajado, chegamos ao momento onde cada participante foi instigado a elaborar, de forma individual, um mapeamento da articulação desses registros coletivos com a sua base prévia de conhecimentos de forma a encontrar um repertório que fizesse sentido para suas pesquisas e práticas.

\section{4a performance: Reconhecimento atento}

\section{Produção de dispositivos disparadores de aprender-fazendo}

Tendo chegado a um repertório partilhado de conceitos e práticas e após cada integrante traçar seu mapeamento particular de apropriação desses conceitos, as ações do grupo concentraramse em construir mecanismos que traduzam partes relevantes deste conjunto, acessíveis aos 
públicos mais diversos. Tais artefatos estão sendo usados pelos próprios integrantes do grupo (embora não-exclusivamente) como dispositivos disparadores de ações-reflexões, úteis às práticas de intervenção de aprendizagem inventiva.

No tempo presente, o grupo está mobilizado para a tradução desses dispositivos disparadores de aprender-fazendo tanto para o meio digital como para o analógico, assim como na condução de pesquisas, eventos e projetos que promovam a manifestação desse repertório de conceitos e práticas de aprendizagem inventiva.

A seguir detalharemos os enfoques conceituais norteadores do projeto e os resultados alcançados até o momento.

\section{Conceitos norteadores do projeto}

O projeto de construção de um repertório comum de conceitos para práticas de aprenderfazendo tem como combustível a ideia de que estamos vivendo em tempos turbulentos, perturbadores, problemáticos, onde a ressurgência é necessária (Haraway, 2017). Partimos do pressuposto de que a Educação Básica Pública é um cenário fértil para essa ressurgência. Contudo, é evidente a situação de precariedade e desassistência pela qual passam nossas escolas. Haraway (2017) nos alerta que é precisamente nesses cenários nefastos onde é preciso inventar formas criativas de estar-com, viver-com, morrer-com, criar-com. Por esse motivo, o Grupo de Estudos Design na Escola da ESDI/UERJ sugere que o Design tem um relevante papel a desempenhar junto à comunidade escolar na promoção de práticas educativas de aprender-fazendo: proposição de artefatos, espaços, comunicações, serviços e interações que instiguem a educação básica de qualidade.

Ainda conforme Haraway (2017), nosso tempo nos incita a criar parentescos em conexões inventivas, ou seja: incorporar a prática de aprender a viver e a morrer bem uns com os outros, considerando a densidade do presente. Pensando com Haraway e tendo como vocação o Design Participativo no contexto da Educação Pública, a missão do Grupo é experimentar formas de viabilizar parentescos entre designers e professores deste meio.

Logo, o Grupo de Estudos reúne integrantes que partilham desta vocação para construirjuntos uma práxis transformadora de ações-reflexões no contexto da educação pública. Nesse sentido, este compromisso põe em evidência a noção de conhecimento como tessitura em rede de múltiplos saberes, valores e crenças a partir de múltiplas interações sociais. Na concepção do conhecimento como redes educativas (Oliveira, 2008), não há superioridade do saber acadêmico sobre as demais formas de conhecimento. Portanto, as propostas de ação do grupo são pautadas pelo esforço de diálogo permanentemente transversal com as minorias periféricas, no espaço de fronteira, entre as culturas, línguas, etnias e saberes (Walsh, 2006). Entendemos que é este incessante movimento da rede dinâmica de inter-relações entre seres humanos e não humanos (Latour, 2004), que garante a permanência de um pluriverso: novos olhares e enfrentamentos ao paradigma dominante que está posto, ou seja, formas outras de ver o universo como uma trama de saberes distintos (Escobar, 2012). 


\section{Resultados e discussão}

A partir de maio de 2020, após a mudança de rumo ocasionada pelo isolamento social, a transposição dos encontros presenciais semanais para videoconferências remotas oportunizou a entrada de novos integrantes ao Grupo de Estudos: estudantes de graduação, pósgraduação, designers formados e professoras da Rede Pública e Privada de Educação do Rio de Janeiro, Paraná e Minas Gerais, somando 19 integrantes. Para além do uso de videoconferências, a possibilidade de estar-junto virtualmente, fazendo uso de ambiências digitais que potencializaram práticas comunicacionais interativas e hipertextuais do ciberespaço, foi decisiva na incorporação de outra forma de presencialidade e participação. A diversidade de saberes e estilos de vida dos integrantes do grupo levou-nos a explorar as potencialidades da cibercultura presentes nas tecnologias digitais em rede. $O$ uso desses mecanismos e as possibilidades de acessá-los de diferentes formas em lugares dispersos favoreceu a colaboração ativa entre pesquisadores e professores, respeitando e valorizando suas particularidades de pertencer a diferentes regiões brasileiras.

\section{1a performance - Leituras e sínteses coletivas}

Para dar conta da produção coletiva do grupo no ciberespaço (Pimentel, 2020), lançamos mão do uso de tecnologias de informação e comunicação acessíveis a todos os integrantes do grupo: 1. fontes de informação: textos e vídeos foram usados como fonte do debate; 2. sistemas de autoria: os editores digitais de texto e apresentações foram usados de forma síncrona e assíncrona para o registro colaborativo dos insights do grupo e também como ambiência de oficinas; 3. mídias sociais: foram usadas com frequência para comunicação e organização das atividades do grupo. Também fizemos uso de diferentes ciberespaços da modalidade AVA - Ambiente Virtual de Aprendizagem - como o Google Sala de Aula (GLS) e o Discord (que mesmo não sendo oficialmente um AVA foi assim apropriado), usando-os como ambiências voltadas para a organização das referências e dos registros coletivos do grupo e também como espaço de acomodação dos canais de conversação síncrona e assíncrona.

Figura 1. Ambiências dos AVA Discord (esquerda) e GSL (direita) acomodando as interações do grupo. Fonte: Grupo Design \& Escola ESDI/UERJ.

A partir do uso destes recursos a troca de saberes entre designers praticantes em diferentes contextos, professoras atuantes na rede pública e privada de Educação Básica e pessoas de diferentes regiões do Brasil favoreceu a consolidação de debates muito proveitosos.

Alguns membros do grupo atuam/atuaram em contextos privilegiados do design e da educação (grandes empresas e escolas da elite privada) que dispõem de tecnologia de ponta. Contudo, houve uma sensível vocação/compromisso do grupo em fazer diferença investigando modos de traduzir práticas oriundas das escolas da elite para outras, que pudessem ser implementadas na rede pública da Educação Básica, a partir de adaptações e usos de tecnologias de baixo custo. Para cumprir este objetivo investigamos propostas pedagógicas provenientes de pedagogos e designers que apresentassem potencial inovador de usos do pensamento projetual, linguagens, objetos, tecnologias e mediações, incluindo as práticas de aprendizagem online.

Por meio dos debates semanais analisamos as proposições de cerca de 15 educadores e/ou designers. Registramos os conceitos e propostas mais proveitosas e aderentes ao projeto fazendo uso dos sistemas de autoria coletiva google docs.

Figura 2. Exemplo de registro coletivo de conceitos e propostas debatido com base na leitura de autores selecionados. Fonte: Grupo Design \& Escola ESDI/UERJ.

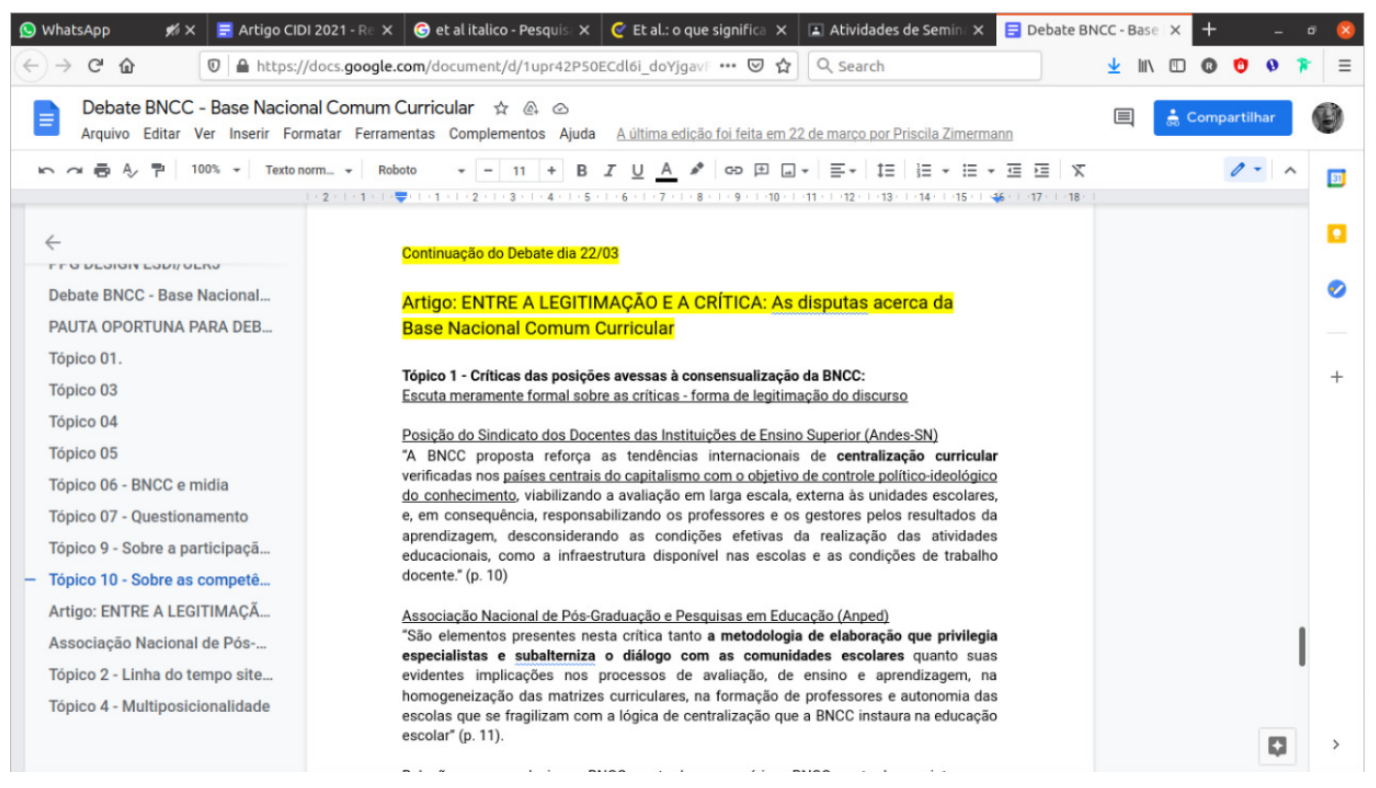

\section{2a performance - Representação Gráfica de Síntese}

Tendo consolidado um registro de conceitos e propostas proveitosas aos objetivos de ação do grupo, foi necessário encontrar um modo de articular esses conhecimentos de forma que pudéssemos enxergar interconexões e vislumbrar brechas ainda não identificadas. Pois, conforme Kastrup \& Passos (2014) o Comum é produzido por meio da transversalização por práticas de participação, inclusão e tradução expressando consistência experiencial e concreta. A construção do comum acompanha práticas consistentes que comunam e criam pertencimento. 
O próximo passo, então, foi a realização de dinâmicas com os próprios integrantes do grupo. Tais atividades funcionaram como dispositivos metodológicos que favoreceram a catalisação colaborativa de ideias.

Para tal, lançamos mão das habilidades de duas integrantes do grupo que realizaram com o coletivo a dinâmica de Representação Gráfica de Síntese (RGS). Conforme Padovani et al (2020), a RGS envolve um processo de construção colaborativa de conhecimento a partir do constante diálogo entre participantes, visando a elucidação e revisão de conceitos teóricos, mediado pela concepção e produção de uma representação gráfica.

Para participar da dinâmica, cada integrante registrou previamente 5 tópicos de destaque dos debates semanais. A dinâmica foi realizada na ambiência digital Miro que, tecnicamente, constitui um sistema de autoria que favorece a colaboração síncrona. Todos os participantes iniciaram a atividade compartilhando o espaço de trabalho e dispondo seus 5 post-its virtuais. Em poucos minutos, conduzido pelas mediadoras, o grupo fez diversas articulações entre os conceitos prévios. Este momento foi muito valioso para todas/os. Em um espaço curto de tempo os conceitos trazidos por cada integrante foram mesclados e ressignificados em sínteses gráficas cada vez mais abreviadas, porém carregadas de sentido para os propósitos do grupo.

Nessas discussões ficou clara para os integrantes do grupo a potência da identificação de laços e pontos de interseção conceitual e prática. Foi interessante perceber que há correlações sutis entre conceitos usados no campo da Educação e do Design: autores potentes de abordagens em ambas áreas (como Paulo Freire, Antônio Fontoura, Montessori, Freinet, José Pacheco, Rita Couto, Nilda Alves, dentre outros), conceitos e estratégias que imbricam esses dois campos (autonomia, afetividade, aprendizagem inventiva, pedagogia por projetos, círculo de cultura, dentre outros).

Após a epifania de iniciar a criação do repertório comum, debatemos o caráter efêmero e permanentemente provisório e aberto a conhecimentos outros que possam trazer ressignificações oportunas a essa síntese. Pensando com Kastrup \& Passos (2014), o comum não é jamais conquistado de modo definitivo. 
Figura 3: sequência de sínteses gráficas colaborativas, realizadas no Miro, convergindo os conceitos trazidos por cada integrante em direção ao traçado dos valores comuns ao grupo. Fonte: Grupo Design \& Escola ESDI/UERJ.

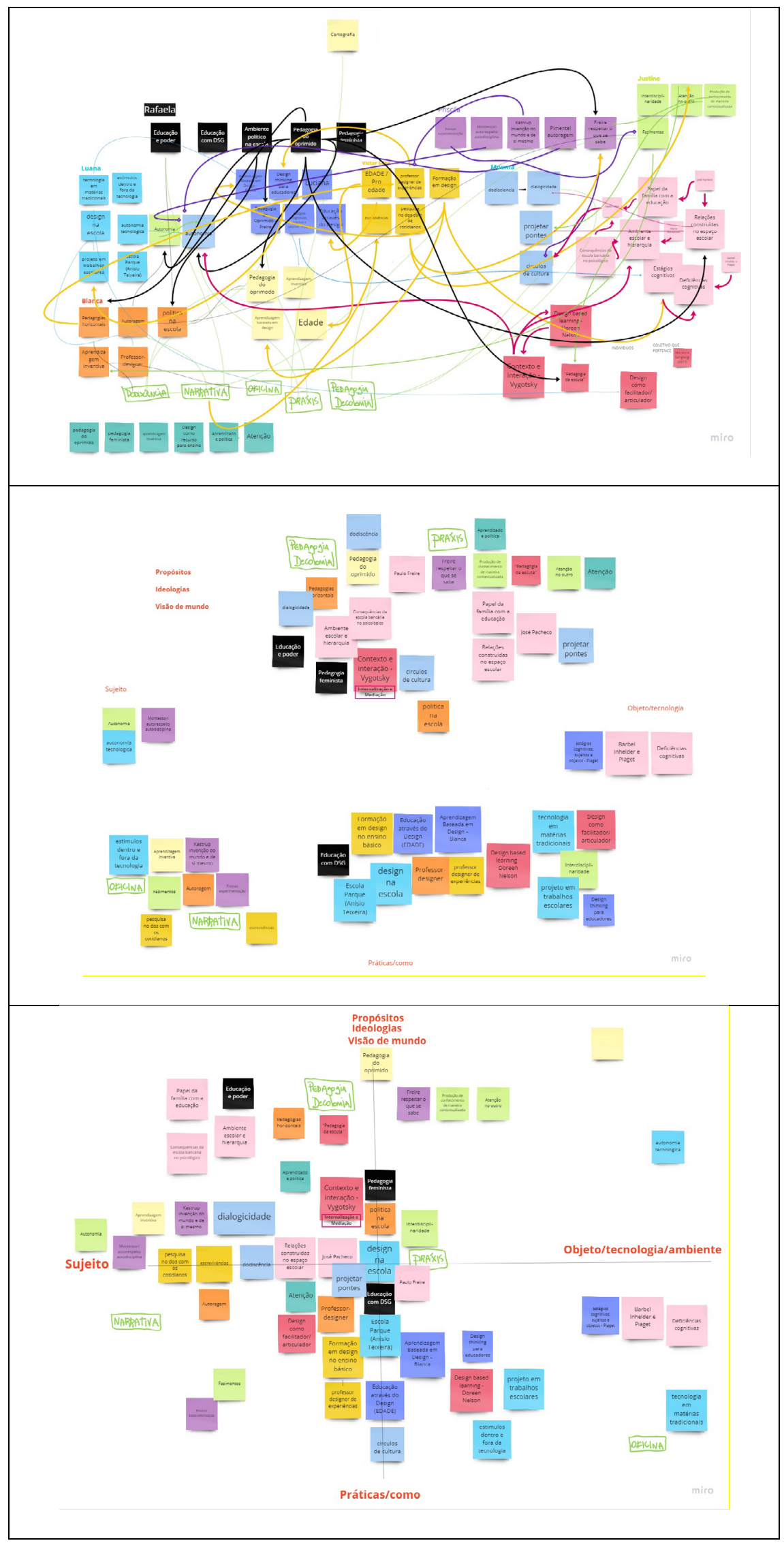




\section{3a performance - Mapeamento individual - a parte no todo}

No passo seguinte, e na intenção de alcançar a diversidade dentro do todo, pois cada integrante tem seus interesses particulares de pesquisa e atuação, cada membro se dedicou a traçar uma síntese individual em forma de mapa de conceitos, com a função de explicitar as inter-relações entre os conceitos do repertório comum preliminar e ideias peculiares relevantes ao seu repertório particular de pesquisa. Os sistemas de autoria utilizados foram de livre escolha de cada integrante. Este foi um momento onde cada participante precisou refletir e articular seus próprios conceitos na intenção de encontrar sua parte no todo. Cada membro também redigiu um breve texto que auxiliou os demais integrantes a perceber nuances do registro particular. A seguir algumas imagens desses registros.

Figura 4. Algumas sínteses individuais em forma de mapa de conceitos traçados por integrantes do grupo. Fonte: Grupo Design \& Escola ESDI/UERJ.
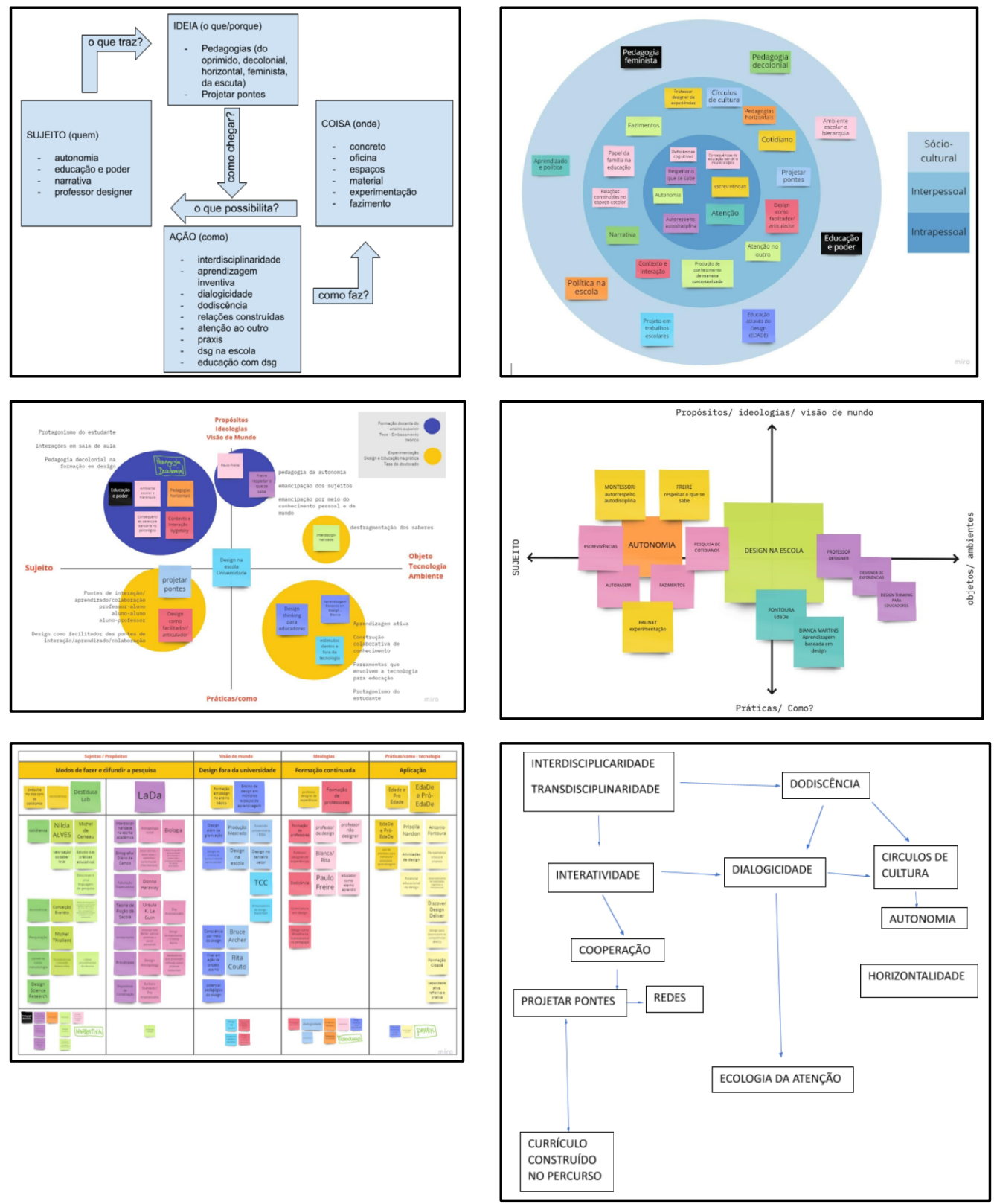


\section{4a performance - Produção de dispositivos disparadores de aprendizagens inventivas}

Tendo chegado a um repertório partilhado de conceitos e práticas e após cada integrante traçar seu mapeamento particular de apropriação desses conceitos, as ações do grupo concentraramse em construir mecanismos que traduzam partes relevantes deste conjunto. Entendemos que temos em mãos um acervo de conceitos originais, concebidos a partir de intensos debates provenientes de atores que praticam atividades pedagógicas visando oferecer aos aprendizes formas instigantes de aprender-fazendo. As traduções deste acervo vem sendo realizadas pelo grupo por meio de mobilizações diversas: seja através da proposição de atividades docentes para praticar esses conceitos (elaboração de cursos, oficinas e sequências didáticas), por meio de pesquisas e projetos (tema de investigações de mestrado e doutorado, projetos de extensão e intervenções na sociedade), na realização de eventos e publicação de artigos para a promoção deste repertório ou ainda mediante a elaboração de publicações didáticas em linguagens acessíveis aos públicos mais diversos incentivando a proposição destas práticas.

A seguir, alguns exemplos de atividades e/ou publicações que traduzem o acervo de conceitos e práticas de aprendizagem inventiva:

Figura 5: Amostras de dispositivos como redes sociais e publicações impressas e digitais que traduzem práticas de aprender-fazendo. Fonte: Grupo Design \& Escola ESDI/UERJ.




Ainda como performances desempenhadas pelo grupo no sentido de cartografar o repertório comum de práticas de aprender-fazendo, realizamos eventos que contribuíram para intensificar a troca de experiências e conhecimentos com outros pesquisadores e membros da sociedade. A saber: Encontro: Jogos e gamificação na sala de aula; Roda de conversa: Antonio Fontoura e o legado do projeto EdaDe - Educação através do Design; Entrevista à Rita Couto: Design e Educação Fertilizações recíprocas; Evento: (Des)Educar Para (Re)Existências:

Design, aprendizagens e invenção; Conferência: Aprendizagem inventiva: a sala de aula como invenção de mundos; Conferência: Designs do sul: possibilidades de desenhos outros;

Conferência Internacional: Aprendizagens em tempos de pandemia: colaboração e narrativas digitais; Encontro Internacional Design \& Educação Infantil; Encontro Nacional: Pesquisa em Design: Estabelecendo pontes virtuais - ESDI/UERJ \& Design/UFPR.

Figura 7: Exemplos de traduções do acervo de práticas de aprender-fazendo por meio de eventos online Fonte: Grupo Design \& Escola ESDI/UERJ.

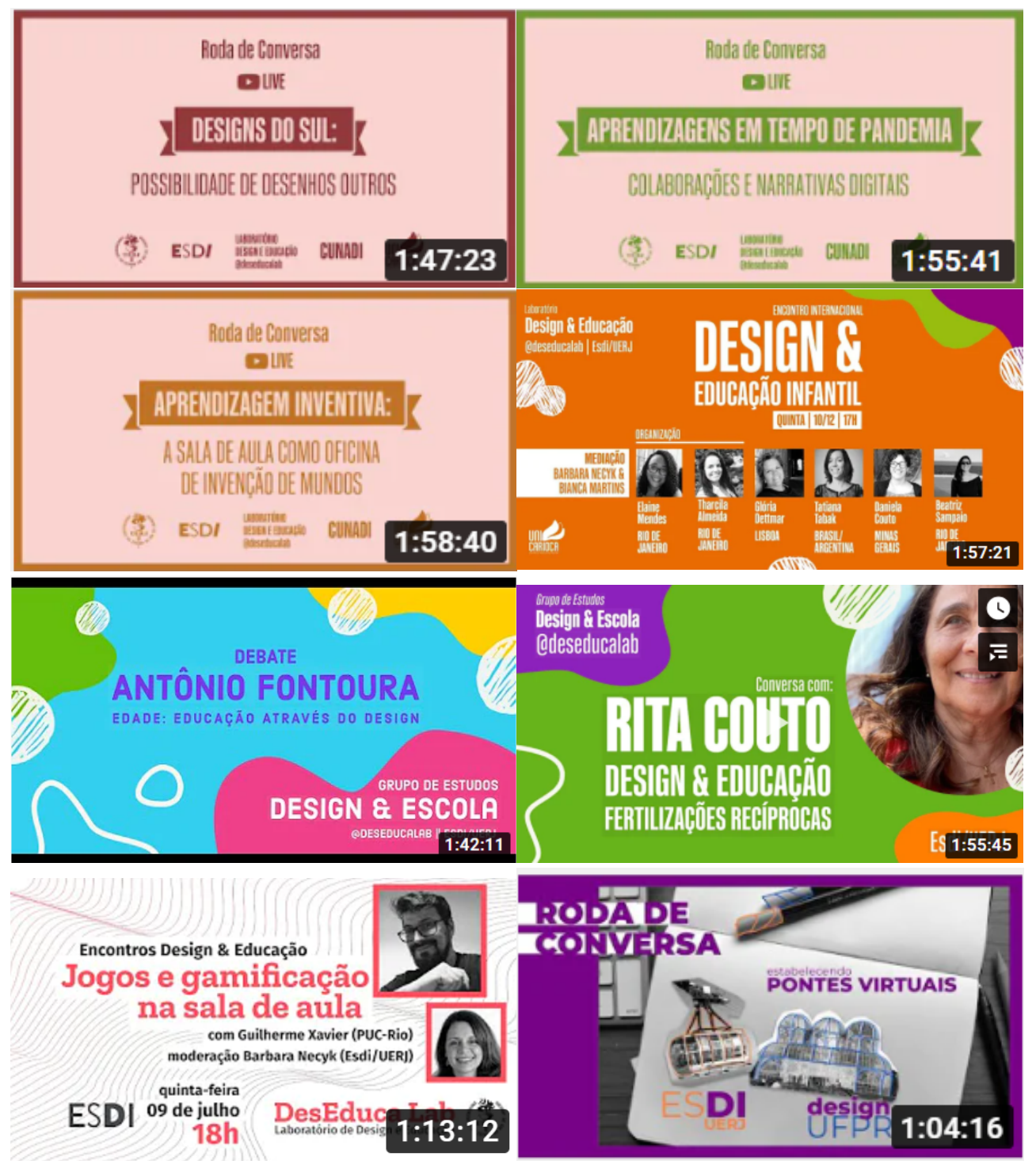


Outro dispositivo que vem sendo desenvolvido trata de uma retomada à síntese elaborada pelo grupo, agora abordada de forma mais detalhada, procurando esboçar um painel de autores significativos ao nosso repertório e os principais conceitos por eles formulados. Referenciando de forma afetuosa Donna Haraway, que encoraja as nossas propostas de cocriação entre professores e designers, apelidamos o repertório comum colaborativo com o nome: Cartografia de parentescos das práticas de aprender-fazendo (Figura 6). Tal mapeamento, permanentemente provisório e aberto a novos aportes, vem sendo elaborado a muitas mãos e contribui para a visualização de interconexões frutíferas entre as diferentes perspectivas adotadas nas pesquisas e intervenções realizadas pelos integrantes do grupo.

Figura 6: Cartografia de parentescos das práticas de aprender-fazendo. Fonte: Grupo Design \& Escola ESDI/UERJ. Artefato de navegação digital. Para uma melhor visualização acesse: https://miro.com/app/board/o9J_IE9r6Oc=/

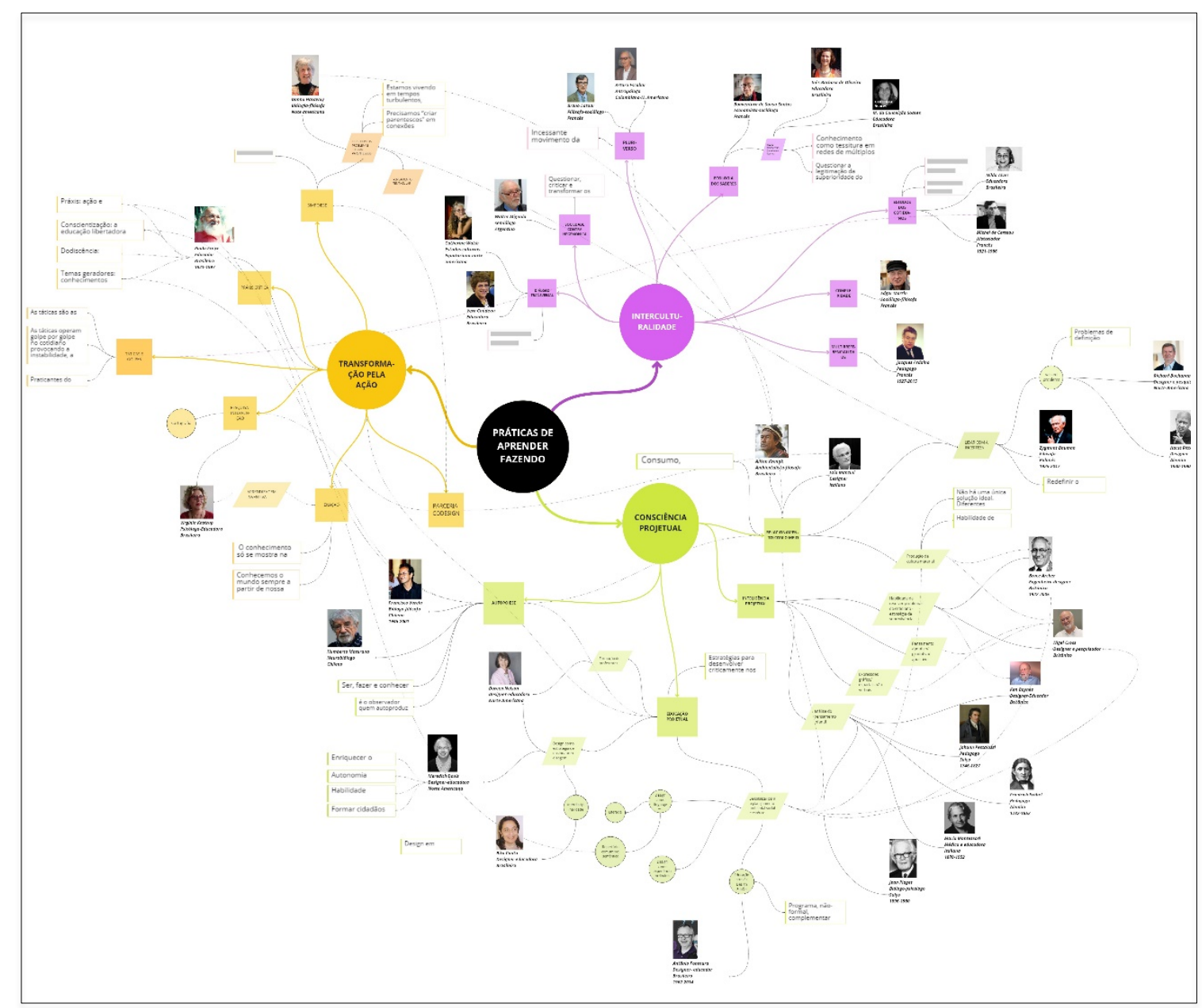

\section{Considerações finais}

Nesta síntese destacaremos algumas lições aprendidas e desdobramentos do trabalho. No período de pandemia e restrições das mais diversas, apesar das dificuldades e desvios de rota, o grupo tirou proveito das facilidades de comunicação e interação oportunizadas pela cibercultura e criou laços conectando pesquisadores de diferentes regiões que atuaram 
juntos na construção de dispositivos para o enfrentamento dos gargalos da educação pública brasileira.

Também ficou notável ao grupo o caráter de inseparabilidade entre conhecer-agir e o agenciamento entre sujeito, objeto, teoria e prática presentes no percurso do processo cartográfico. A produção do mapeamento coletivo de um repertório comum inaugurou nos designers e professores envolvidos novas potências de ser e agir a partir da mediação destas congruências.

Ainda, vale comentar que a partir da elucidação de conceitos que respaldam as práticas de aprender-fazendo alcançamos a articulação de duas instâncias da UERJ que atuavam de forma bem isolada: a ESDI e o CAp-UERJ. Hoje, membros da Universidade e da Escola atuam no mesmo grupo de pesquisa imbricando debates e proposta entre Design e práticas escolares.

Contudo, não temos apenas pontos positivos a destacar. Os debates também evidenciarem as fragilidades de atuação no contexto escolar brasileiro. Destacamos uma pequena parte do que esteve presente nas conversas: a precarização das infraestruturas para o funcionamento básico das escolas; as dificuldades de trabalho dos professores, seja pela falta de compromisso do poder público com à categoria - como o atraso da vacinação, por exemplo seja pelas múltiplas jornadas de trabalho que conferem escasso tempo para preparação de aulas e acompanhamento dos alunos; a dificuldade de atuação frente a reatividade das comunidades onde a escola é, por vezes, a única instituição do poder público a frequentar o local; e questões relacionadas à desmotivação pessoal para fazer diferença diante das adversidades e cerceamentos da própria cultura escolar.

No entanto, com protagonismo e esperança, as atividades do grupo seguem a pleno vapor e esta cartografia dos parentescos tem nos ajudado na construção de interlocuções para a proposição de atividades concretas. Foi por intermédio da visualização destas pontes criadas que vêm sendo planejadas: intervenções nas práticas de alfabetização de adultos (EJA) junto à uma professora da Cidade de Santos Dumont/MG; dinâmicas para instigar habilidades socioemocionais na Educação Infantil com uma professora do bairro Rocha Miranda/RJ; estratégias de fortalecimento da autoestima a partir das aulas de Artes no Ensino Fundamental em colaboração com uma professora atuante na Cidade Alta/RJ e intervenções de educação para a sustentabilidade e inclusão em parceria com uma professora do Ensino Fundamental do bairro de Realengo/RJ. Todas atuantes de escolas da Rede Pública de Educação. E isso nos move a seguir adiante no percurso do fazer-com participativo professores e designers.

\section{Agradecimento}

Sem os integrantes do grupo este artigo não seria possível: André Coutinho, Barbara Emanuel, Cristina Jardim, Daniel Cherpe, Daniela Couto, Elaine Mendes, Justine Hack, Luana Batista, Lucas Nonno, Luciana Bertoso, Lucimei Ricas, Raoni, Moema Orichio, Priscila Zimermann, Raquel Leal, Taiany Marfetan, Victor Silba.

O presente trabalho foi realizado com apoio da FAPERJ - Fundação Carlos Chagas Filho de Amparo à Pesquisa do Estado do Rio de Janeiro - Brasil, por meio do Auxílio Recémcontratado - ARC/FAPERJ. 


\section{Referências}

Cantù, D., Corubolo, M., Simeone, G. (2012). A Community Centered Design approach to developing service prototypes. Servces Service Design and innovation Conference, Cocreating services. Espoo, Finland, 8-10 February.

Barros, R. \& Passos, E. (2009). Cartografia como método de pesquisa-intervenção. In: Barros, R., Kastrup, V., Escóssia, L. (Org.). Pistas do método de cartografia: pesquisa-intervenção e produção de subjetividade. 1a ed. Porto Alegre: Sulina, v. , p. 17-31.

Escobar, A. (2012). Más allá del desarrollo: post desarrollo y transiciones hacia el pluriverso. Revista de Antropología Social, 21, 23-62.

Freire, Paulo. (1987). Pedagogia do oprimido. $17^{\mathrm{a}}$ ed. Rio de Janeiro: Paz e Terra.

Haraway, D. (2016). Staying with the Trouble: Making kin in the Cthulhucene. Duke University Press, Durham e Londres. 296 páginas.

Kastrup, V. \& Passos, E. (2014) Cartografar é traçar um plano comum. In: Passos, E., Kastrup, V., Tedesco, S. (Orgs.). Pistas do método da cartografia: a experiência da pesquisa e o plano comum. Porto Alegre: Sulina. p. 15- 41.

Latour, B. (2004). Políticas da natureza: como fazer ciência na democracia. Tradução: Carlos Aurélio Mota de Souza. Bauru, SP: EDUsc.

Oliveira, I. (2008) Estudos do cotidiano, pesquisa em educação e vida cotidiana: o desafio da coerência. ETD - Educação Temática Digital, Campinas, v.9,n. esp., p.162-184, out.

Padovani, S., Bueno, J. \& Oliveira, J. (2020) Representações Gráficas de Síntese (RGS): em busca de uma elucidação do conceito. In: Revista Infodesign. São Paulo, v. 17, n. 1, p. 149 $-151$.

Walsh, C. (2006). Interculturalidad y (de)colonialidad: diferencia y nación de otro modo. En: Desarollo e interculturalidad, imaginario y diferencia: la nación en el mundo andino, (27-43). Quito: Academia de la Latinidad.

\section{Sobre a autora}

Bianca Martins. Dra. Esdi/UERJ, Brasil bmartins@esdi.uerj,br 